\title{
Study of fatigue behaviour of 7475 aluminium alloy
}

\author{
B B VERMA*, J D ATKINSON ${ }^{\dagger}$ and M KUMAR \\ Department of Metallurgical Engineering, Regional Engineering College, Rourkela 769 008, India \\ ${ }^{\dagger}$ School of Engineering, Sheffield Hallam University, Sheffield S1 1WB, UK
}

MS received 23 October 2000; revised 13 February 2001

\begin{abstract}
Fatigue properties of a thermomechanically treated 7475 aluminium alloy have been studied in the present investigation. The alloy exhibited superior fatigue life compared to conventional structural aluminium alloys and comparable stage II crack growth rate. It was also noticed that the fatigue crack initiated from a surface grain and the crack extension was dominated by ductile striations. Analysis also revealed that this alloy possessed fracture toughness and tensile properties superior to that noticed with other structural aluminium alloys. Therefore the use of this alloy can safely reduce the overall weight of the aircraft.
\end{abstract}

Keywords. 7475 Aluminium alloy; fatigue life; fatigue crack growth; cyclic cleavage; ductile striations.

\section{Introduction}

Aluminium and its alloys are being used successfully in a wide range of applications, from packaging to aerospace industries. Due to their good mechanical properties and low densities, these alloys have an edge over other conventional structural materials. Aluminium alloys continue to be the dominating structural materials for aircraft. In most of the aircraft, the air-frame consists of about $80 \%$ aluminium by weight (Zehnder 1996). Now-a-days, the cost reduction for aircraft has become an important criterion in many airlines and the selection of material is done on the basis of life cycle approach. The composites are very competitive materials for aircraft structural applications. However, they are generally considered to have higher initial cost, require more manual labour in their production and are more expensive to maintain.

The 2024 aluminium alloy remains as an important aircraft structural material due to its extremely good damage tolerance and high resistance to fatigue crack propagation in T3 aged condition (Zehnder 1996). The low yield stress level and relatively low fracture toughness, however, limit the application of this alloy in the highly stressed region. The greatest potential of commercial exploitation is offered by the medium strength $\mathrm{Al}-\mathrm{Zn}-\mathrm{Mg}$ alloys such as 7075, 7050, etc. The applications of these alloys remained restricted due to their low toughness and environmental sensitive fracture in service, particularly under cyclic loading condition (CarciaCordovilla et al 1994). It has been reported by several investigators that the fatigue crack growth rate enhances

\footnotetext{
*Author for correspondence
}

when exposed to aqueous saline environments a most common aggressive environment; for these alloys (Holroyd and Hardie 1983). The $7475(\mathrm{Al}-\mathrm{Zn}-\mathrm{Mg}-\mathrm{Cu})$ alloy is a controlled toughness alloy developed for applications that require a combination of high strength, superior fracture toughness and resistance to fatigue crack propagation both in air and aggressive environment. The 7475 aluminium alloy is basically a modified version of 7075 alloy. Properties in 7075 alloy are improved by reducing its contents of iron and silicon, and altering quenching and ageing conditions. These modifications in 7075 alloy result in the development of 7475 alloy having fine grain size, optimum dispersion and highest toughness value among the aluminium alloys commercially available at high strength level (Jahn and Luo 1988). It is also reported that the corrosion resistance and corrosion fatigue behaviour of 7475 alloy are excellent (Jahn and Luo 1988). In general, its performance is better than that of many commercially available high strength aerospace aluminium alloys such as 7050 and 7075 alloys.

The 7475 alloy in the form of sheets are commercially available in T61 and T761 tempers, whereas the plates are usually tempered to T651, T7351 and T7651 conditions. The plate has the strength very close to some tempered 7075 alloy, whereas the fracture toughness values are up to $40 \%$ greater than that of 7075 alloy in the same temper conditions. The 7475 alloy, in the form of sheets and plates, is presently being specified for fracture critical components of high performance aircraft, where high fracture toughness is a major design consideration.

The objective of the present investigation is to characterize S-N curve and crack growth behaviour of 7475 aluminium alloy in T7351 temper condition. In this paper, the fracture toughness and tensile performance of this 
alloy have also been compared with those of other conventional aluminium alloys. Attempts have also been made to study the fatigue fracture surfaces of the tested specimens.

\section{Experimental}

\subsection{Material and specimens}

The material used in the present investigation was $12.5 \mathrm{~mm}$ thick plate of 7475 aluminium alloy of composition (in wt\%) Al-5.73 Zn-2.14 Mg-1.15 Cu-0.02 Cr$0.05 \mathrm{Fe}-0.04 \mathrm{Si}$. The alloy under investigation has been supplied in T7351 temper condition (yield stress: $495 \mathrm{MPa}$ and elongation: 14\%). The T7351 treatment involves solution treatment at $470^{\circ} \mathrm{C}$, water quenching and controlled stretching from $1 \cdot 5-3 \%$ followed by artificial ageing in two stages: first at $121^{\circ} \mathrm{C}$ for $25 \mathrm{~h}$ and second at $163^{\circ} \mathrm{C}$ for a period of $24-30 \mathrm{~h}$.

Specimens for S-N curve study were machined from the supplied plate with $\mathrm{L}$ radial orientation. The dimensional details of the specimen are presented in figure 1a.
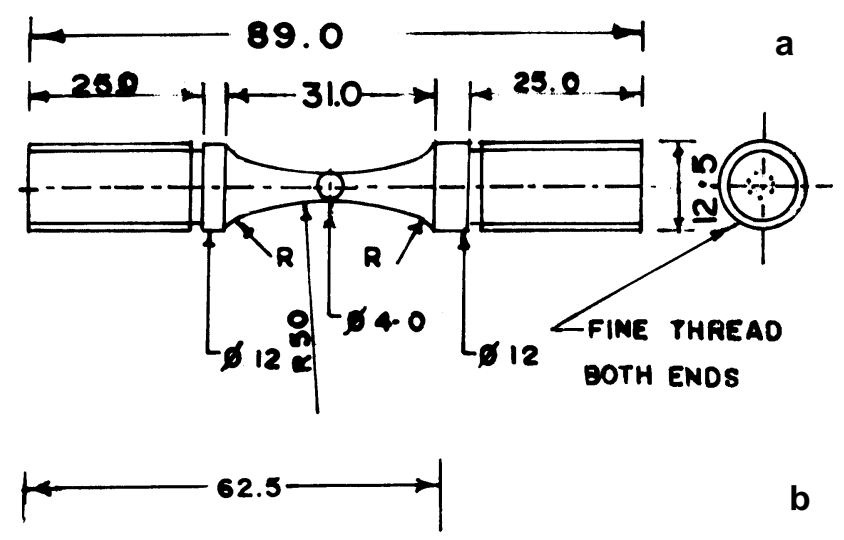

b
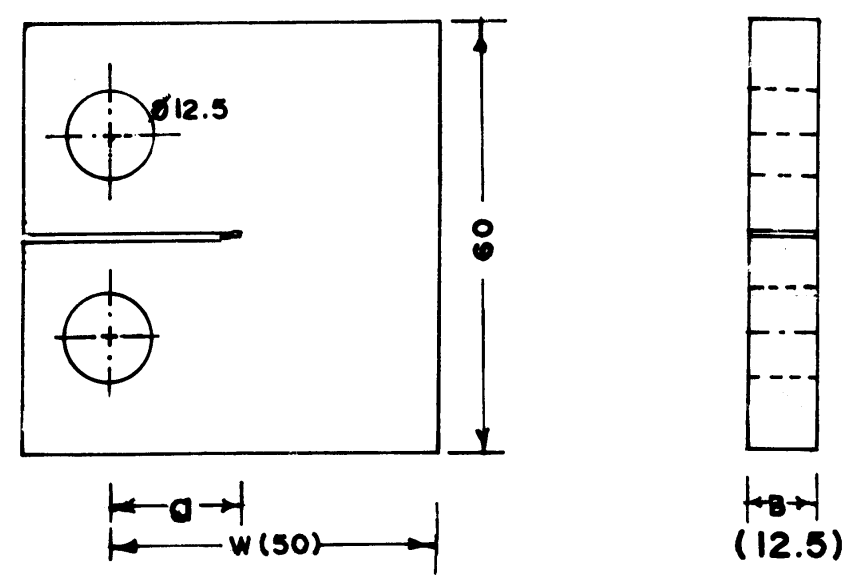

\section{Dimensions in $\mathrm{mm}$.}

Figure 1. Dimensional details of a. fatigue life estimation specimen and b. CT specimen.
Prior to testing, the specimens were diamond polished to an $1 \mu \mathrm{m}$ finish and then degreased. To study the fatigue crack growth behaviour, compact tension (CT) specimens (50 mm wide and $12.5 \mathrm{~mm}$ thick) were machined in TL and LT orientations. The dimensional details of CT specimen are presented in figure $1 \mathrm{~b}$. The polished and degreased CT specimens were then pre-cracked to a total crack length of nearly $17 \mathrm{~mm}(a / w=0 \cdot 34)$ before actual test.

\subsection{Fatigue testing}

Fatigue life characterization in terms of nominal stress (S-N curve characterization) was performed using a $100 \mathrm{kN}$ servohydraulic Mayes testing machine under load control condition. Completely reversible push-pull (stress ratio, $R=-1$ ) sinusoidal load cycles at a frequency of $3 \mathrm{~Hz}$ were used for all the tests.

The fatigue crack growth study was conducted on pre-cracked CT specimens in tension-tension, sinusoidal loading condition at a stress ratio $(R)$ of 0.2 using $100 \mathrm{kN}$ Mayes testing machine. All the crack growth studies were conducted at a frequency of $1 \mathrm{~Hz}$. The propagating fatigue crack was monitored with the help of electrical potential difference technique.

\section{Results and discussion}

3.1 Comparative study of tensile properties and fracture toughness of aluminium alloys

Based on the data compiled by Verma (1997), an attempt has been made to compare tensile properties and fracture toughness of some important structural aluminium alloys, as highlighted in figure 2 . It may be seen in the figure that 2024-T351 alloy has high ductility and good fracture toughness (both in TL and LT orientations) but has relatively low yield strength. On the other hand, 7075 alloy

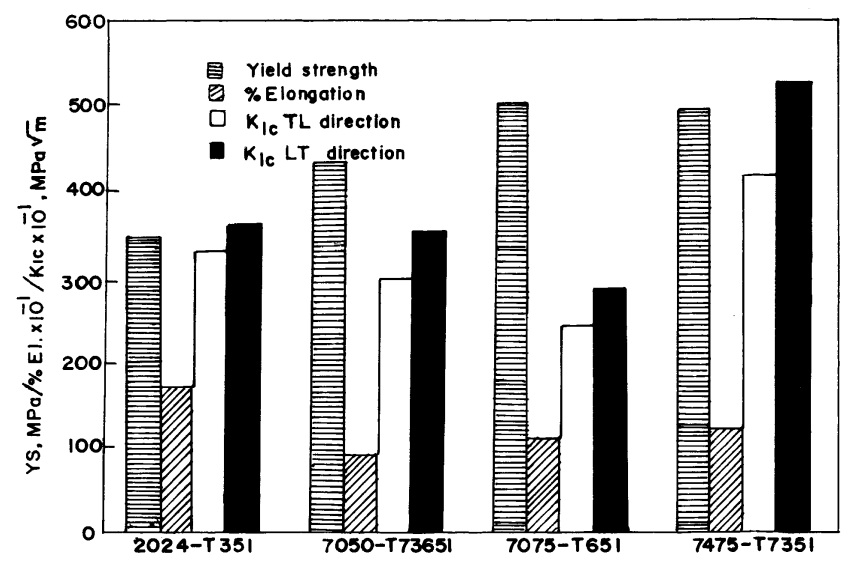

Figure 2. Comparative representation of yield stress, \% elongation, and $K_{\mathrm{IC}}$ in different aluminium alloys. 
under T651 temper condition has yield strength over $500 \mathrm{MPa}$. The reported fracture toughness of this alloy (7075-T651) in TL and LT orientations are nearly $24 \mathrm{MPa} \sqrt{\mathrm{m}}$ and $27 \mathrm{MPa} \sqrt{\mathrm{m}}_{\mathrm{m}}$ respectively but has low level of ductility. The 7475 alloy under T7351 condition possesses very high fracture toughness (42 MPa $\sqrt{\mathrm{m}}$ and $52 \mathrm{MPa} \sqrt{\mathrm{m}}$ in TL and LT orientations respectively). Whereas, in comparison to 7075-T651 alloy, the 7475T7351 alloy has marginally inferior yield strength but slightly superior ductility. In view of these facts, the use of properly treated 7475 alloy is expected to safely reduce the overall weight of aerospace structure, an important criterion for such applications.

\section{$3.2 S-N$ curve and its comparative analysis}

The stress vs number of cycles to failure curve for the 7475-T7351 alloy (at $R=-1$ ) has been presented in figure 3. It is observed that at an alternating stress level of $250 \mathrm{MPa}$, the number of cycles to failure is $1.86 \times 10^{5}$ whereas, at alternating stress of $195 \mathrm{MPa}$, the number of cycles to failure is increased to $2.47 \times 10^{6}$.

The data from literature for 2024-T3 (Osgood 1982), 2017-T4 (Ishihara et al 1995), and 7075-T6 (Verma 1997) alloys are superimposed for comparison. Comparative study of the curves for these materials indicates that 2024-T3 and 7475-T7351 alloys perform better than 7075-T6 alloy over the entire investigated stress range. The difference seems to be prominent, particularly, where lives are short i.e. in high stress region. The 7475-T7351 alloy appears to exhibit comparable performance with respect to 2024-T3 alloy in the high stress region. In the lower stress region, 7475-T7351 alloy seems to be superior to all other alloys, as shown in figure 3. It has been reported by a few investigators (Santner and Eylon 1979; VanOrden et al 1979) that reduced iron and silicon contents do not always result in improved fatigue resistance. An appropriate thermomechanical treatment (TMT)

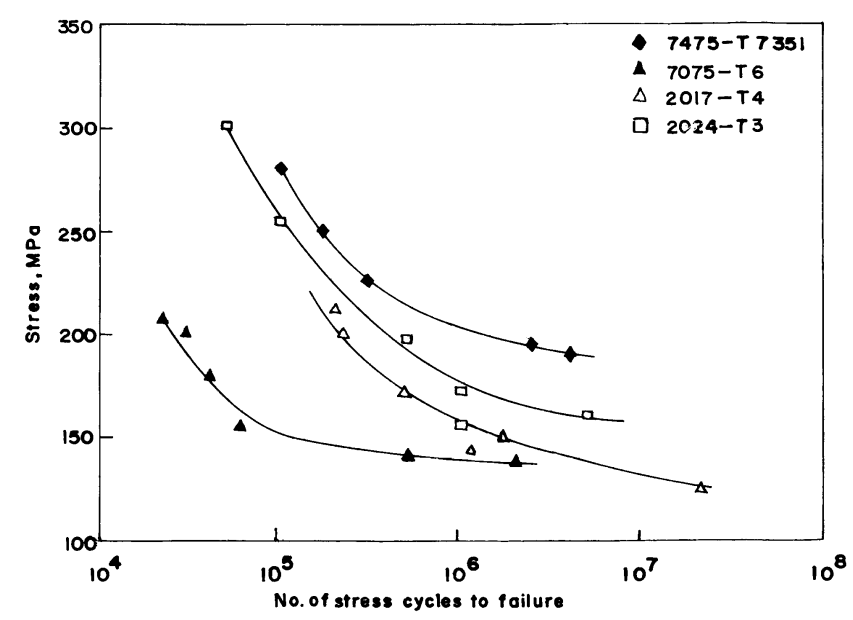

Figure 3. S-N curves for different aluminium alloys. makes the precipitates finer and more uniformly dispersed. Under such conditions, the stresses are more uniformly distributed across the specimen and hence reduce stress concentration on insoluble particles. This may delay the crack initiation and results into better $\mathrm{S}-\mathrm{N}$ curve performance (Jahn and Luo 1988). It may also be concluded from the observation that 7075-T6 is not a suitable alloy for applications where high tensile stresses are expected. The 7475 alloy under T7351 temper condition performs better than 2024-T3, 2017-T4 and 7075T6 alloys over the entire range of stress.

\subsection{Crack growth study}

To study the crack growth behaviour, crack extension vs number of stress cycle plots were generated and slopes at different crack lengths were measured with the help of a computer software. Corresponding values of basic stress intensity factor (SIF) range were also calculated using appropriate polynomial equation. To illustrate the crack growth behaviour, the slope of the curve $\mathrm{d} a / \mathrm{d} N$ i.e. fatigue crack growth rate (FCGR), is plotted as a function of stress intensity range $(\Delta K)$ for $7475-\mathrm{T} 7351$ alloy in TL and LT orientations and presented in figure 4 . It may be seen from the figure that in both the orientations, the

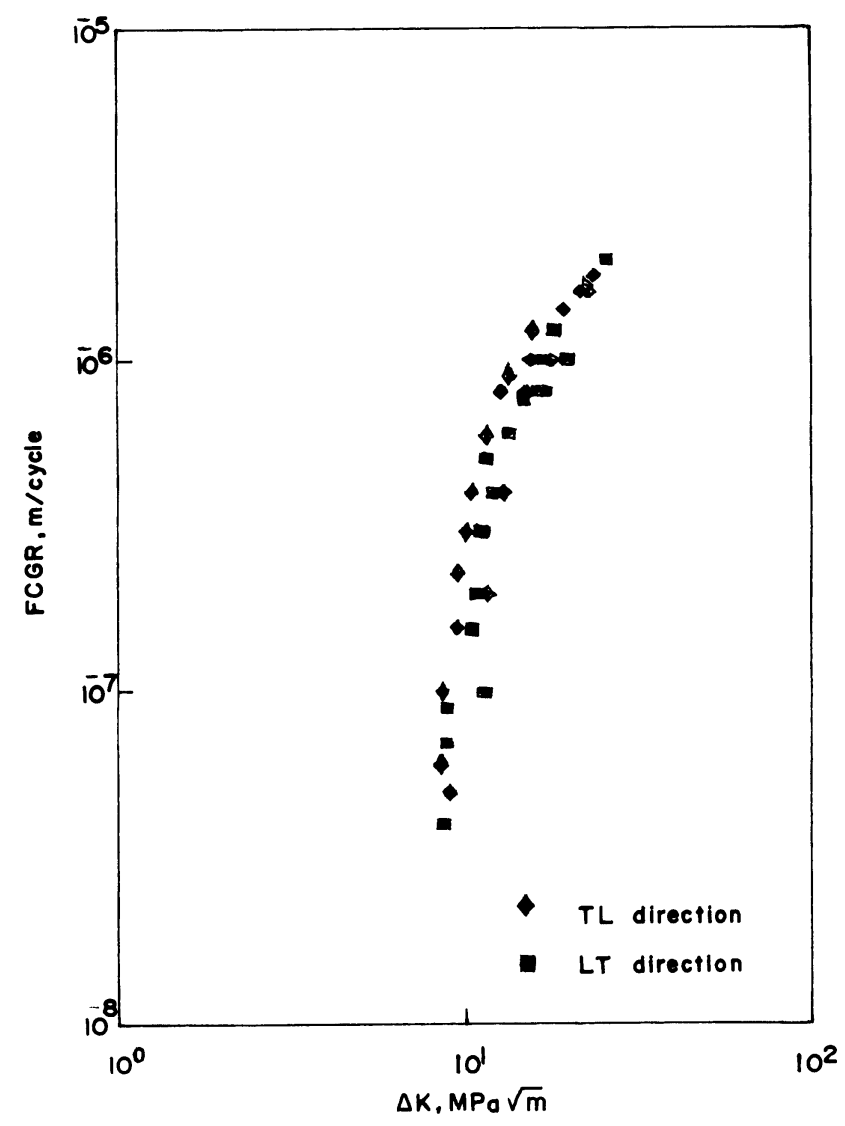

Figure 4. Fatigue crack growth behaviour of 7475-T7351 alloy in TL and LT orientations, $R=0 \cdot 2$. 
crack growth rate is comparable. This appears to be due to reduced content of impurity elements and optimized TMT resulting into very fine and uniformly distributed precipitates in alloy. Similar crack growth rate in both the orientations, over the entire investigated range of $\Delta K$, may be due to the isotropic nature of the material. It may be recalled that the distribution of precipitates has little effect on stage II crack extension (Santner and Eylon 1979; Truckner et al 1979). An attempt has been made to count inclusion content of the alloy under investigation and a commercial 2024-T3 aluminium alloy by using an image analyzer. The inclusion count in 2024-T3 alloy was found to be 6.2 times more than that in the investigated alloy. This indicates superiority of thermomechanically treated 7475 alloy over 2024-T3 alloy, as far as inclusion count is concerned.

In figure 5, an attempt has been made to compare the crack growth behaviour of thermomechanically treated 7475 alloy with some commercially important Al-alloys, such as 2124-T852, 7010A-T7352, 7012-T7352 and 7075-T6 (Buratti et al 1986; Verma 1997). It is observed that the initial crack growth in 2124, 7075 and 7475 alloys occurs at $\Delta K \approx 7 \mathrm{MPa} \sqrt{\mathrm{m}}$. However, 7010 and 7012 aluminium alloys need relatively lower $\Delta K$ level to maintain same crack growth rate. It is also noticed that stage II crack growth behaviour in 7475 aluminium alloy is com-

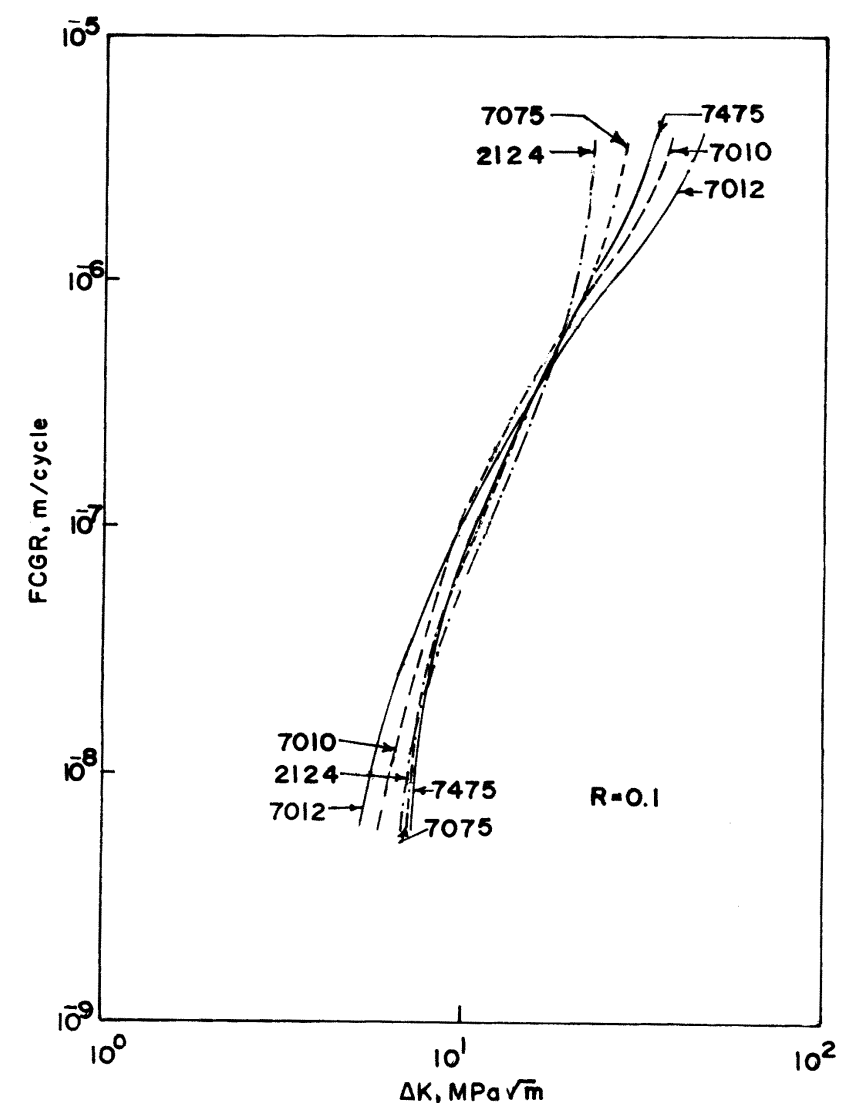

Figure 5. Fatigue crack growth behaviour of different aluminium alloys in TL orientation, $R=0 \cdot 1$. parable with other aluminium alloys, as examined in figure 5. This indicates that though the thermomechanically treated 7475 aluminium alloy has superior strength, ductility, fracture toughness and fatigue life, however, exhibits stage II crack growth rate comparable to other commercially important aluminium alloys. Here, it is worth to note that the precipitates and their distribution have little effect on resistance to stage II fatigue crack growth (Buratti et al 1986; Santner and Eylon 1979; Truckner et al 1979).

\subsection{Fractographic study}

The fractured surface of a specimen, tested for generation of its S-N curve, has been examined under SEM and the fractographs obtained have been presented in figures $6 \mathrm{a}$ and $b$. It may be seen in figure $6 a$ that the fatigue crack is not initiated from any surface inclusion. Rather, the flat and featureless facet, located on the specimen surface,
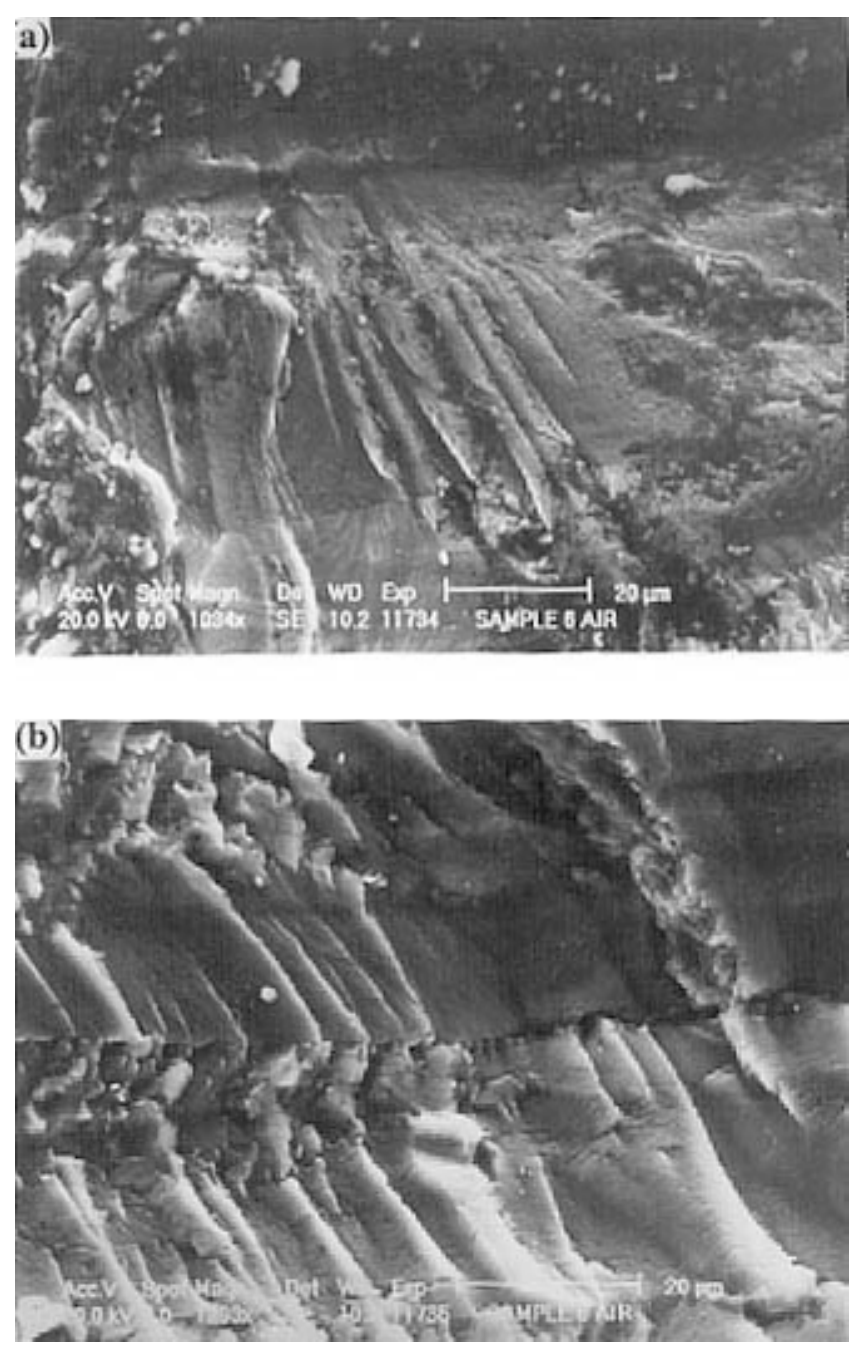

Figure 6. SEM fractographs of a S-N curve test specimen a. in the vicinity of crack originating surface and b. at $375 \mu \mathrm{m}$ from crack originating surface. 

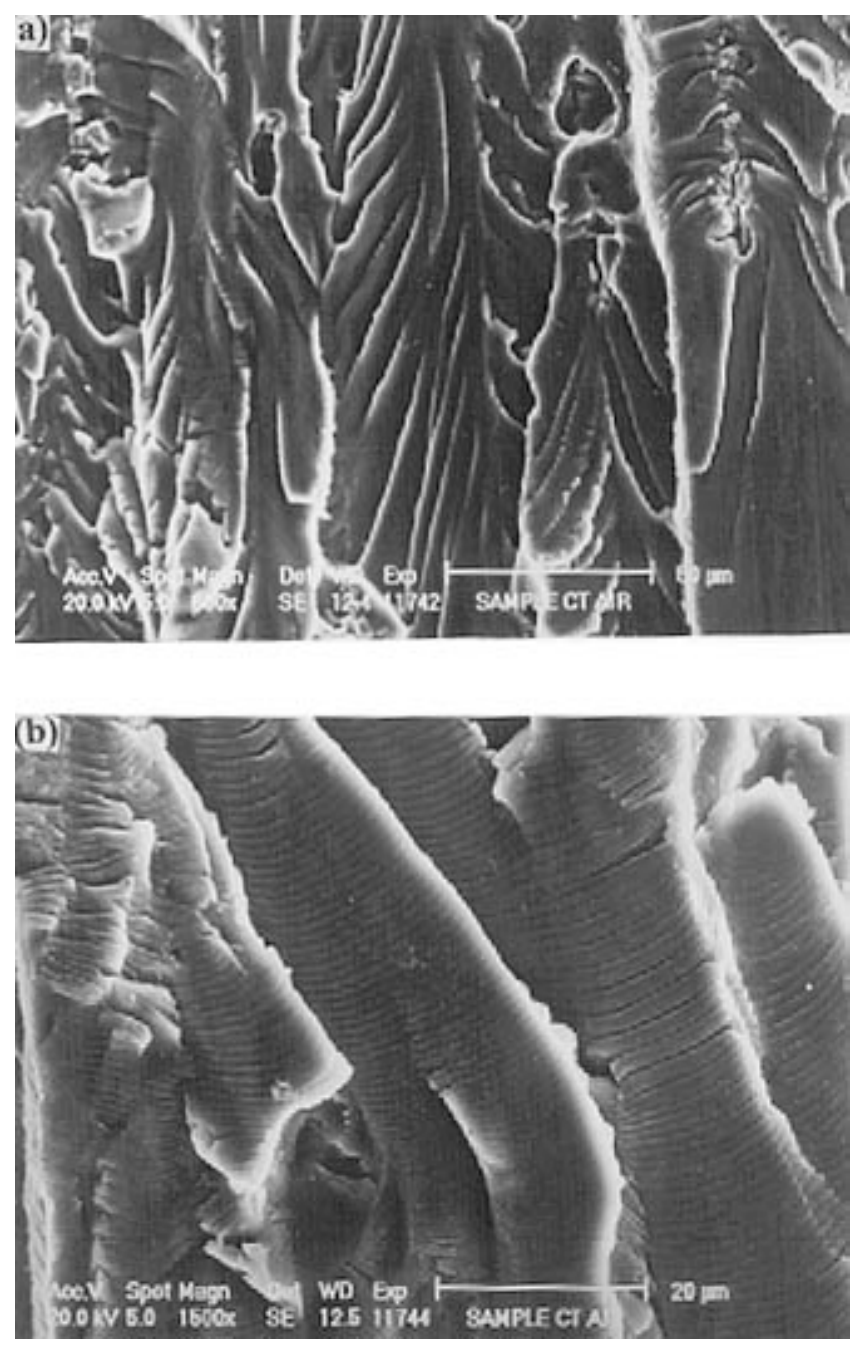

Figure 7. SEM fractographs of a CT specimen a. at $\Delta K$ $\approx 12.7 \mathrm{MPa} \sqrt{\mathrm{m}}$, and b. at $20.5 \mathrm{MPa} \sqrt{\mathrm{m}}$.

appears to be the origin of stage I crack. Tokaji and Ogawa (1992) have also reported similar fractographs for a low carbon steel, an aluminium alloy and pure titanium. In aluminium alloys, constituent particles provide sites for fatigue crack initiation. As outlined by Suresh (1996), and Jahn and Luo (1988), the relative probability of crack initiation increases with particle thickness. It has also been cited that the surface grains are the most probable location for crack initiation in metals and alloys of high purity. In the present alloy, the crack could not initiate from impurity particles due to their low concentration, small size and uniform distribution over the matrix (Suresh 1996). The featureless crack extension is followed by cleavage-like crack emanating from grain boundary (figure 6a). These failure modes, termed as cyclic cleavage, do not represent cleavage fracture in true sense because they exhibit slow progressive failure (occurs near threshold region) rather than a brittle separation (Suresh 1996; Irving and Beevers 1974). This is an indication of long fatigue life of 7475-T7351 alloy at low
$\Delta K$ region. The fracture surface of the same specimen at $375 \mu \mathrm{m}$ from the crack originating surface reveals ductile striations and tearing ridges; a high energy fracture. This is an indication of high toughness material which has excellent resistance to fatigue crack propagation (figure 6b) (Jahn and Luo 1988). It also appears that no secondary crack is present in the examined region (figures $6 \mathrm{a}$ and b). This further supports the possibility of remarkable fatigue performance of the alloy.

The fracture surfaces of CT specimens have been examined under SEM and are presented in figures $7 \mathrm{a}$ and $\mathrm{b}$. It may be noticed that at $\Delta K \approx 12.7 \mathrm{MPa} \sqrt{ }$, the fracture appears to be cyclic-cleavage with ductile striations. Fractograph of specimen at $\Delta K \approx 20.5 \mathrm{MPa} \sqrt{\mathrm{m}}$ (figure $7 \mathrm{~b}$ ) shows the ductile striation dominated feature. The observations in figures 6 and 7 indicate change in the mode of fracture with increased level of SIF. The average striation width at this level of $\Delta K$ is $1.7 \times 10^{-6} \mathrm{~m}$; a value very close to the measured crack growth rate $\left(1.6 \times 10^{-6} \mathrm{~m} /\right.$ cycle) by electrical potential difference technique. It may be noted from figure $7 \mathrm{~b}$ that secondary cracks or dimples are not seen even at $\Delta K \approx 20.5 \mathrm{MPa} \sqrt{\mathrm{m}}$. This could be due to high yield strength of the alloy and very low level of inclusions.

\section{Conclusions}

From the present investigation, the following conclusions have been drawn:

(I) The analysis has confirmed that thermomechanically treated 7475 aluminium alloy has high strength, reasonable ductility and excellent fracture toughness and therefore, the use of this alloy can safely reduce the overall weight of aerospace structures.

(II) In comparison to other structural aluminium alloys, 7475 (under T7351 temper condition) exhibits superior fatigue life.

(III) The stage II crack growth behaviour of this alloy is comparable to other structural alloys.

(IV) Crack initiation in this alloy took place from surface grain, typical in high purity metals and alloys.

(V) The mechanism of stage II crack extension changed from cyclic-cleavage at low $\Delta K$ to ductile striation at relatively high $\Delta K$.

\section{Acknowledgements}

The authors gratefully acknowledge the project sponsors, the British Council Division, New Delhi and R.E. College, Rourkela.

\section{References}

Buratti M, Russo E Di and Giordano G 1986 Aluminium technology, conf. proc. (ed) T Sheppard (London: Inst. of Metals) p. 468 
Carcia-Cordovilla C, Louis E, Pamius A, Caballero L and Elices M 1994 Mater. Sci. \& Engg. A174 173

Holroyd N J H and Hardie D 1983 Corr. Sci. 23527

Irving P E and Beevers C J 1974 Mater. Sci. \& Engg. 14229

Ishihara S, Mc Evily A J and Shiozawa K 1995 Fatigue Fract. Engg. Mater. Struct. 181311

Jahn M T and Luo Jin 1988 J. Mater. Sci. 234115

Osgood C C 1982 Fatigue design (New York: Pergamon Press) 2nd ed p. 439

Santner J S and Eylon D 1979 Metal. Trans. A10 841

Suresh S 1996 Fatigue of materials (Cambridge: Cambridge University Press) pp. 119 and 209
Tokaji K and Ogawa T 1992 in Short fatigue crack (eds) K J Miller and E R de los Rios (London: Mech. Engg.) p. 85

Truckner W G, Staley J T, Bucci R J and Thakker A B 1979 AFMT-TR-76-169

VanOrden J M, Krupp W E, Walden E and Ryder J T 1979 J. Aircraft 16327

Verma B B 1997 TCT report (Sheffield: Sheffield Hallam University)

Zehnder J 1996 in Aluminium: Technology, application, and environment, a profile of a modern metal (ed) Dietrich G Altenpohl (Pennsylvania: TMS Warrendale) p. 319 